\title{
A review on the relevance of standards for silicone insulating liquids used in Cable Sealing Ends
}

\author{
Introduction
}

Internationally recognised standards by organisations such as ASTM and IEC are widely known and relied upon in all areas of engineering. One example in high voltage electrical engineering is the employment of standards giving material specifications to make decisions on the suitability of materials for a specific purpose. However, by their nature as reference documents, some of these standards lack reasoning and explanations about the derivation of the values stated. Others were written many years ago with only cursory updates being made at reviews since. A recent survey on ground and submarine cable systems based on data of the past 25 years suggests that faults in cable terminations and joints could accommodate up to 34\% failures [1]. Another study on cable systems used in offshore cable connections shows a clear divergence in the reliability metrics resulting in underestimation of the failure rate [2]. This highlights the need to identify gaps between standards and practices. Whilst investigating silicone liquids for cable sealing ends (CSE), several limitations and contradictions between standards that exist were identified by the authors. These discrepancies and deficiencies caused uncertainty in the industry as they did not provide clear guidance to asset owners.

More specifically, new dielectric materials have surfaced as electrical insulators over the last decade in the pursuit of meeting new infrastructure demands and becoming more environmentally friendly (decarbonisation). This presents a challenge to the engineers responsible for commissioning new electrical equipment into service. According to a review on condition monitoring techniques, there are significant differences between data created under laboratory conditions and field data [3]. Both the lack of an update process considering in-field variations and the lack of explanations given in standards as to why specific values are stated have given a cause for concern.

This review will consider six key properties of silicone liquids: sample handling, viscosity, dielectric parameters, breakdown voltage, DC conductivity and moisture content. This discussion is done in an attempt to highlight the key deviations between the standards and actual experimental values and observations. Contradictions between standards purportedly for the same purpose (and associated trade-offs involved in choosing one standard over the other) will also be highlighted as a part of this report, as well as possible shortcomings of the standards. Based on the common observations, a list of suggestions is included in an attempt to improve the current practices. Although the scope of this review is limited to silicone liquids, the aim is to invite further studies to critically review existing international standards developed for specific applications.

Discussion on available international standards for handling and analysing silicone liquids

CSE for extruded cable systems is expected to operate for approximately 40 years without the need to open them for an invasive inspection of the insulation system. They are considered "maintenance free". This is, in part, due to the exceptional chemical, thermal and dielectric properties of the silicone liquids which are frequently the liquid insulator within CSE [4], [5]. Over the last two decades, there have been issues reported with XLPE CSE of different designs and manufacturers, with few consistent features between the designs and failures. Silicone liquids have been present in many of the designs, which has highlighted the need for a better understanding of this liquid and its application in CSE [6]. Such type problems result in significant disruption to the operation of transmission and distribution networks, can introduce additional network risk and introduce additional challenges for safe working.

Silicone insulation liquids, also known as polydimethylsiloxane (PDMS) are used as liquid insulation in cable sealing ends (CSE) of cross-linked polyethylene (XLPE) cables. New silicone liquid is relatively free from impurities, but it may contain small amounts of reactive chlorosilane or catalyst residues from its manufacturing process. The presence of such impurities along with external factors, such as moisture and thermal stress, could manifest in the accelerated ageing of the CSE [7]-[9]. Thus, assessing the oil properties can indicate the overall health of the equipment. Many properties are identified that could be assessed to judge if a given sample of silicone liquid is fit for use in service according to the listed standards or experimental results. It must be noted that there are no specific standards for silicone liquids in CSEs. Test limits for service-aged silicone insulation liquids in transformer applications are given in IEEE C57.111 [10]. One major difference to a CSE is that transformers 
undergo regular maintenance, thus the insulation can be accessed for regular testing and, if needed, filtered or replaced. Table 1 compares several parameters given across various available standards that are found relevant for CSE. Here IEEE C57.111 has specified different acceptable values for silicone liquids used in a transformer, as-received (prior to filling equipment) and post service liquid [10]. In the first look itself, these standards show some inconsistencies in the range of acceptable values for different properties. On a closer inspection, it is found that while there is a need to improve accuracy/ error range for measurement of parameters such as dielectric permittivity, other parameters like viscosity could use a revision in values applicable for use in a specific application. Parameters such as DC resistivity could use an overall reconsideration for its applicability as a health indicator due to measurement constraints. A discussion highlighting these issues in detail is presented in this article. Scope of improvement in measuring techniques, storage methods is also included. Most importantly, the validity of the specified acceptable range of values in light of literature findings, in-field experiences and applicability of their use for silicone oil for CSE are detailed in the following sections.

Viscosity

Under typical operating conditions, it is assumed that silicone liquids exhibit Newtonian behaviour. If the silicone liquid is polymerised or depolymerised in service, the molecular chain length changes, which manifest as changes in the viscosity of the liquid. Thus, changes in the viscosity of the liquids indicate structural or chemical changes in the liquids such as chain length reduction or oxidation [8]. The viscosity of silicone liquids is key for a high voltage device such as a transformer since the liquid is 'a principle factor in affecting heat transfer by convection flow of the liquid' [10] and managing the temperature of such devices is paramount for both safety and operational efficiency. This is also one of the reasons why e.g. ester-based insulation liquids require transformers to be redesigned, in order to account for the significantly different viscosity [5]. For CSE, on the other hand, this requirement is not critical, since the CSE does not require the liquid to be circulated within cooling channels. In fact, some PDMS insulation used in practice needs to be heated up before filling the CSE to enable them to flow and stretch the definition of the word "liquid". Thus, the utility of viscosity measurement is limited as an identifier for ageing processes or contamination. A recent review highlights possible alternate chemical analysis, which could perform more accurate analysis faster and with lesser sample requirements [11].

The scope of the IEC 69836 standard, 'Specifications for silicone liquids for electrical purposes' includes guidance for use of silicone liquid in transformers and other electrical equipment, such as cable accessories [12]. It signposts specific standards for conducting experiments designed to assess the suitability of the liquid for service.

Table 1: Recommendations for silicone oils in use of transformers and other equipment according to different standards

\begin{tabular}{|c|c|c|c|c|c|c|}
\hline $\begin{array}{l}\text { Material } \\
\text { Property }\end{array}$ & $\begin{array}{l}\text { IEC } 60944 \\
\text { transformer } \\
<35 \mathrm{kV}\end{array}$ & $\begin{array}{l}\text { IEC } 60944 \\
\text { high-stress } \\
\text { transformer } \\
\text { oil }\end{array}$ & IEC 69836 & $\begin{array}{l}\text { IEEE } \\
\text { C57-111* } \\
\text { as } \\
\text { received }\end{array}$ & $\begin{array}{l}\text { IEEE C57- } \\
111^{*} \text { new } \\
\text { transformer } \\
\text { oil }\end{array}$ & $\begin{array}{l}\text { IEEE C57- } \\
111 * \text { aged }\end{array}$ \\
\hline $\begin{array}{l}\text { Colour and } \\
\text { Appearance }\end{array}$ & $\begin{array}{l}35 \\
\text { Clear, } \\
\text { colourless }\end{array}$ & $\begin{array}{l}35 \\
\text { Clear, } \\
\text { colourless }\end{array}$ & $\begin{array}{l}\text { Clear, free } \\
\text { from } \\
\text { sediment }\end{array}$ & $\begin{array}{l}15 \text { (ref } \\
\text { ASTM-D- } \\
2129)\end{array}$ & $\begin{array}{l}\text { Clear, particles } \\
\text { free }\end{array}$ & $\begin{array}{l}\text { Clear, } \\
\text { colourless, } \\
\text { particles free }\end{array}$ \\
\hline $\begin{array}{l}\text { Kinematic } \\
\text { viscosity (Cst) }\end{array}$ & & & $\begin{array}{l}40 \pm 4 \text { at } 40 \\
{ }^{\circ} \mathrm{C}\end{array}$ & $47.5-52.5$ & $47.5-52.5$ & $47.5-52.5$ \\
\hline $\begin{array}{l}\text { Flashpoint } \\
\left({ }^{\circ} \mathbf{C}\right)\end{array}$ & & & $>240$ & $>300$ & & \\
\hline Fire point $\left({ }^{\circ} \mathbf{C}\right)$ & $>300$ & $>300$ & $>330$ & $>340$ & $>340$ & $>340$ \\
\hline $\begin{array}{l}\text { Water content } \\
(\mathbf{p p m})\end{array}$ & Not specified & Not specified & $<50$ & $<50$ & $<50$ & $<100$ \\
\hline $\begin{array}{l}\text { Breakdown } \\
\text { voltage }(\mathbf{k V})\end{array}$ & $>30$ & $>45$ & $>40$ & $>35$ & $>30$ & $>25$ \\
\hline $\begin{array}{l}\text { DC resistivity } \\
(\Omega \mathrm{m})\end{array}$ & $1 \times 10^{11}$ & $1 \times 10^{12}$ & $\begin{array}{l}>1 \times 10^{13}(90 \\
\left.{ }^{\circ} \mathrm{C}\right)\end{array}$ & $\begin{array}{l}1 \times 10^{14} \\
\left(25^{\circ} \mathrm{C}\right)\end{array}$ & & \\
\hline $\begin{array}{l}\text { Dissipation } \\
\text { factor }\end{array}$ & Not specified & Not specified & $\begin{array}{l}<0,001 \text { at } 90 \\
{ }^{\circ} \mathrm{C}, 50 \mathrm{~Hz}\end{array}$ & $\begin{array}{l}<0,01 \text { at } \\
25^{\circ} \mathrm{C}\end{array}$ & $<0,1$ at $25^{\circ} \mathrm{C}$ & $<0,2$ at $25^{\circ} \mathrm{C}$ \\
\hline Permittivity & & & $\begin{array}{l}2,55 \pm 0,05 \text { at } \\
90{ }^{\circ} \mathrm{C}\end{array}$ & & & \\
\hline
\end{tabular}


This standard also gives some values expected for service-suitable liquids. Apart from appearance, most expected values deviate from those specified in IEC 60944 (Table 1). It also states that viscosity should be measured at $40{ }^{\circ} \mathrm{C}$ using ISO Standard 3104 (Methods of test for petroleum and its products) and be $40 \pm 4 \mathrm{~mm}^{2} / \mathrm{s}$ [13]. This can be more difficult to do than a simple measurement at room temperature in practice, and the question needs to be addressed if the IEC standard originally designed for petroleum and its products is valid for silicone liquids.

Elsewhere, the 'IEEE guide for Acceptance of Silicone insulating liquid and its maintenance in transformers' [10] states that measurements should be made according to ASTM D445 (Standard Test Method for Kinematic Viscosity of Transparent and Opaque Liquids) and be between 47.5-52.5 cSt at $25^{\circ} \mathrm{C}$. Helpfully, this guide clearly states the accepted viscosity range does not change with service life, in other words, at all points in time, the silicone liquid must be within the range quoted above. Of course, for a CSE this is not being monitored, since they are considered maintenance-free and it would only be established after disassembly if the liquid would still be within acceptable values. However, reports of a highly viscous liquid with the development of flocculation at the bottom are reported from in ex-service silicone liquids from the CSE unit [14]. The presence of verdigris contamination typically found on the conductor stalk is also reported to adversely affect the viscosity of silicone liquid in a CSE. The report suggests that contaminated liquid turns into a partial gel-like solution [15]. Reports also suggest that for new liquids with viscosity much higher than the standard specified values are being used in practice for CSE [4]. Such a varying range of acceptable viscosity values shall be considered while extending the application of current standards for silicone liquids used for CSE.

Clearly, there is overlap in scope between the two standards - a transformer uses silicone liquid for electrical purposes - and the acceptable ranges given also overlap. But since temperature affects viscosity, it is conceivable that a sample may be within the acceptable limit of one standard but not the other. In such a case, the operator might be uncertain which standard to follow. It is an unfortunate reality that much know-how rests not within the written pages of standard documents but with those who wrote them. For long-established organisations, new generations of engineers therefore often struggle to maintain (or build) HV assets following old design documents.

If standards provided more specific guidance regarding the ranges, quoted beyond the simple 'liquid degradation, contamination' given in the IEEE guide, this may aid the operator in making an informed decision about the suitability of the liquid for an application. Alternatively, complementary tests could be proposed, like thermal conductivity with associated acceptable limits.

\section{Dielectric Dissipation Factor and Relative Permittivity}

The dielectric dissipation factor $(\tan (\delta))$ and relative permittivity $\left(\varepsilon_{\mathrm{r}}\right)$ of an insulating liquid are measured to quantify its dielectric polarization and losses during operation [16]. The values obtained can be dependent on the test conditions and many variables such as test cell configuration, applied voltage level, uniformity of sampling, external noise, and temperature can all affect the measurement. Dielectric response data is utilised to determine the presence of contamination and ageing status of the insulation, making it crucial to ensure uniformity of external factors [17]. Chen et al, [18] have reported enhancement in dissipation factor in ex-service silicone liquids from CSE units. Their analysis indicates the usefulness of dielectric data in predicting the deformation of the macromolecular chain leading to depolymerisation. Another work studying the impact of verdigris contamination from the cable stalk in the liquid indicates that ageing results in higher permittivity and losses. This could be attributed to enhanced copper content in the aged sample [15].

IEC 60247 specifies the procedures to be followed for permittivity and $\tan (\delta)$ measurements for insulating liquids [16]. It states the requirements of the test cell, including that there should be a sufficient distance between the guard and measuring electrodes such that the test cell can withstand the applied voltage (this is not specific to liquids). The applied voltage limit is given as the maximum electric stress of $250 \mathrm{~V} / \mathrm{mm}$ unless specified otherwise. In liquids, the consistency of the distance between electrodes is not given by the sample, but by the structure of the test cell. It would be useful to complement the data with the allowed frequency sensitive error range. For example, the standard states two values of $\tan (\delta)$ should not differ from each other by more than $.0001 \pm 25 \%$ of the higher of the two values. This could be a problem for measurements taken at higher frequencies where the value goes in the range of $10^{-5}$. An analysis of sonication treated silicone liquids aged in the laboratory to mimic electrical stress on the liquid inside a CSE showed variation in $\tan (\delta)$ magnitude in the order $10^{-4}$ [19]. Similar changes were observed in ex-service silicone liquids from four different CSE [18].

IEC 61620 provides the procedure for simultaneous measurement of conductance and capacitance to calculate the dielectric dissipation factor of insulating liquids [20]. The cleanliness of the test cell, time taken between two measurements after reaching temperature equilibrium, and environmental factors such as temperature and 
humidity of measurement are liable to affect the readings. The standard also specifies the need for proper labelling of samples tested with details regarding the date, place, time and temperature of sampling. Although the standard includes a repeatability and reproducibility index for determining acceptable values, instructions like, "one measurement on a single sample is enough", do mean those are not mandatory.

\section{Breakdown Voltage}

Recent failure reports of CSE indicate a direct impact of degradation on the breakdown strength (BDS) of the dielectric liquid. In XLPE CSE, contamination from corrosion products from copper top bolts is reported to cause breakdown of the dielectric liquid [7]. In theory, knowing the breakdown voltage of an insulating liquid means that one knows the intrinsic dielectric breakdown strength (BDS) of the liquid. The intrinsic BDS can only be estimated under very well-defined conditions and on the scale of $\mathrm{ml}$ of liquid volume, which is of course not relevant for large volumes used in HV assets. In practice, different experimental set-ups, along with many other factors such as temperature, particulates, electrode configurations, and gas bubbles can affect the breakdown strength measurement. IEC 60944 specifically mentions that a reduction in the breakdown voltage may be due to the presence of water or particulate contamination. This means that comparing and validating dielectric liquids for use based on breakdown voltages alone is not a reliable method. The conclusion in CIGRE technical brochure 436 summed it up eloquently: 'the measured AC breakdown voltage of an insulating liquid mostly represents the oil quality rather than oil characteristic itself' [21].

In 'Specifications for silicone liquids for electrical purposes' (IEC 69836) [12] it states that the AC breakdown voltage should be measured according to IEC publication 60156 and should have a minimum value of $40 \mathrm{kV}$ [22]. It is worth noting that the IEC publication 60156 states that the test cell volume must be within $350-600 \mathrm{~mL}$, the electrodes may be brass, bronze or austenitic stainless steel and that stirring of the liquid is optional. These all introduce more variables and, although it is stated that there is no significant difference seen between results, where tests were performed with and without stirring when needed. When comparing results between different testing facilities or laboratories, the more variables are free to choose, the greater the deviation between the results, and the lower the confidence one can have in comparing the results. Thus, any value quoted in a standard can be seen as a reference point but not necessarily as a target.

The electrical conductivity of a material is one of the important factors that influence its breakdown strength. Electric conductivity significantly increases with the temperature as a result of both the increased dissociation of oil molecules and the decreasing oil viscosity [23]. Discrepancies in viscosity values may thus affect the breakdown voltage measurements. Highly viscous silicone liquid can be tested by increasing the temperature at pouring time. Sufficient standing time should be allowed for the air bubbles to escape before taking any measurements. To incorporate testing of viscous liquids, the standards must include acceptable values of breakdown voltage at a higher temperature.

IEC 60944 states that the silicone liquid in transformers should have a breakdown voltage $>30 \mathrm{kV}$ and for compact, high-stress transformers this should be $>45 \mathrm{kV}$. Note that these values are not given in $\mathrm{kV} / \mathrm{mm}$, which gives no indication regarding the applied electric field on the insulation, rather the equipment terminal voltage rating. The standard refers the user back to IEC 69836 above for the measuring protocol. Although the general standard for silicone liquid for electrical purposes and the standard for silicone liquid in transformers differ in terms of the quoted acceptable breakdown strength value, the reader is not provided with any comment or reason given for the three separate acceptable values. This makes it difficult for the reader to fully understand, adequately interpret and apply these standards to a given HV asset or application.

It is noticeable from Table 1 that there is no general agreement between those standards, and that there are key parameters that are not mentioned in one or the other. For example, only IEC 69836 refers to the value of permittivity, while IEC 60944 does not even specify water content or viscosity.

\section{DC conductivity}

The electrical properties of silicone liquids are very sensitive to the preparation and conditioning procedures. Even small amounts of impurities and residual water alter the electrical properties of silicon liquid [24]-[26]. The aged liquid is more prone to partial discharges, which leads to decreased resistivity [27]. For dielectric liquids, the nature and concentration of impurities control the conductivity and so, the conductivity greatly depends on the sample purity.

Concerns surrounding the feasibility of measuring the DC conductivity of silicone liquids for CSE, respectively any material with such a low conductivity, have been published elsewhere [4]. The applicability of the test cell set-up described in IEC 60247 and ASTM D1169 [16], [28] were assessed using finite element modelling in order 
to establish the measurable current. The results suggested that the electrode size required to gain a clearly detectable current for commonly used electrometers would have to be at least $0.2 \mathrm{~m}^{2}$. However, according to the above standards, test cells with significantly smaller electrodes are deemed suitable. Thus, the minimum active electrode area needs to be specified, depending on the electrometer detection limit and expected liquid conductivity, rather than suggesting a range of (too small) test cell designs currently found in standards.

\section{Moisture Content}

If moisture contaminates the insulation liquid, it typically reduces the effectiveness of the dielectric. A decrease in the breakdown strength of oil with high moisture content is observed as a result of the fact that water is a polar molecule that is easily absorbed by impurities in the oil. Under the action of an electrical field, these impurities can accumulate and form a bridge. CIGRE report states that a high level of particle pollution is a leading cause of insulation damage in converter transformers with voltage levels of $400 \mathrm{kV}$ and above [29]. Since the exposure of electrical equipment to moisture both from the atmosphere and from the climate conditions is inevitable, knowing the moisture content and keeping the water content below a certain limit is critical [30]. By way of example, Suwarno et al. [30] reported that whilst below $50 \mathrm{ppm}(50 \mathrm{mg} / \mathrm{kg})$, changes to the water content had little impact on the liquid, but above this point, the DC dielectric breakdown strength decreased, tan delta increased and the resistivity decreased significantly.

It is observed that different dielectric liquids have different saturation limits which are mostly governed by their chemical structures. For example, at room temperature, the moisture saturation point of silicone liquid is $230 \mathrm{ppm}$ whereas for mineral oil it is 50ppm. Ester liquids, which have been proposed for $\mathrm{HV}$ applications, can have even higher moisture content [31]. For an operator who has the most experience with mineral oil, the moisture content of a perfectly safe silicone liquid could be alarming. One method of avoiding such confusion based on absolute value is the use of a common scale such as relative moisture content, which is calculated as the ratio of absolute moisture (ppm) to the saturation level of the respective material.

A report compares the relative moisture content the relationship between $\mathrm{AC}$ breakdown voltage and the moisture content of silicone liquids, mineral and ester liquids. For ester liquids, the range varies from $65-75 \%$ for natural esters and around $85 \%$ for synthetic ester Specifically, the silicone liquid relative moisture content at breakdown voltage minimum is $\sim 68 \%$ whereas mineral oil is $75 \%$ [21].

IEC 69836 states that water content can be determined via two methods: IEC publications 814 and 733 and that the maximum water content for untreated, as received liquid is $50 \mathrm{mg} / \mathrm{kg}$. However, this standard stops short of quoting a value or threshold range safe for operation. This is a severe limitation since $50 \mathrm{mg} / \mathrm{kg}$ is well below the saturation point of $220 \mathrm{mg} / \mathrm{kg}$ [21]. Ideally, a CSE remains sealed, unaffected by moisture ingress but in fault conditions such as O-ring failure, cases of atmospheric water exposure over a typical service life of at least 20 years will mean that water content can rise above this value over time. For accurate asset management, one must have a stipulated acceptable water content level for the dielectric liquid in operation probably unique to the specific application. This would ensure that the liquid sampling and measurements can be performed, and if necessary, steps can be taken to rectify the situation.

Understandably, though, those used to mineral oil and considering only the ppm values are alarmed at the comparatively high-water content of silicone liquid, and even higher values for ester-based insulation liquids. This has led to silicone liquid being wrongly accused of being unsuitable for electrical purposes if it can contain this much water, when not taking into account the chemical stability of silicone insulation liquids [21].

All of the new silicone liquids that were suitable and ready for their use in CSE and other electrical purposes that we recently tested had a water content greater than $50 \mathrm{mg} / \mathrm{kg}$. Recent research on the comparison of liquid dielectrics for insulation in CSE showed that silicone liquid has a lower affinity to moisture. The results indicate that the changes in chemical and dielectric properties of moisture-aged silicone liquid are negligible at $125 \mathrm{ppm}$ moisture content [5]. Research undertaken by Liland et al. on 100 CSE in Norway confirms this and found that the mean moisture content was around 90 to $100 \mathrm{ppm}$ [32], which is double the saturation limit of mineral oil. As it stands, we are not aware of a value or range of values given by any standard, cable manufacturer, transmission or distribution company, against which "maintenance-free" assets such as CSE would be monitored in terms of moisture content. 
Before discussing the standards relevant to specific material properties, it is worth starting with the fact that all of the standards discussed herein highlights the importance of uniform sampling techniques that simultaneously exclude the possibility of introducing contaminants not causing degradation of the liquid. For example, IEC 60475, which details procedures for sampling different types of insulating liquids, suggests that samples should be taken from regions of high contamination. It highlights the importance of the use of protective gloves, regular cleaning and replacement of sampling equipment, to ensure a minimal impact of external factors during sampling and transportation of samples [33]. A report on user's experience with cable accessories, specifically emphasizes on the importance of training and troubleshooting by staff handling the cable accessories [34].

IEC 60944 was specifically drafted for silicone liquids and details ways to assess the quality of the liquid during use in transformers rated up to $35 \mathrm{kV}$ [35]. The standard mentions the need to adhere to all precautions during sampling to avoid erroneous test results. The standard suggests many possible techniques for assessing the liquid and gives some values expected for service-suitable liquids. However, this standard suggests that DC conductivity measurements performed according to IEC 60247 are suitable methods for silicone insulation liquids, which contradicts our recent findings, discussed briefly below and published elsewhere [4].

ASTM D923 specifies that the samples need to be stored in sealed clear or amber coloured glass bottles, to avoid damage from moisture, dirt and contamination [36]. However, we have observed that commercially available silicone liquids are typically sold, sent, collected and stored in polymer containers. Depending on the type of polymer used, the quality of the liquid received for investigation might be affected, hence reduces the reliability of the test results obtained and makes ASTM D923 not practical for current use. Specifically, IEC 60475 [33] notes that measuring water content, dielectric strength and dissolved gas is the only representative if the samples were stored in non-permeable glass containers. This goes some way explaining the discrepancies between standards and practical experience.

The abovementioned standards don't consider some practicalities regarding logistics, storage, transport and installation of HV equipment that transmission and distribution system operators need to deal with. The use of glass jars for the delivery of large quantities of silicone liquid is simply not practical. While certain parameters, such as the viscosity, should be reasonably invariant after an initial test, others such as the moisture content are significantly affected by storage conditions, transport and handling. In the aforementioned case of CSE, if samples are taken in the field just before installation, or when the liquid is received in a centralised storage location after delivery will affect the outcomes. More on that in the discussion below.

\section{Suggestions}

The discussion so far has focussed on several standards, literature and observations relevant to the use of silicone liquid in CSE. This discussion could help to merge experiences and theory and develop more reliable and wellreasoned data for use for a utility engineer. The following list of suggestions can be considered while revising the current instruction manuals and standards,

- Standards dealing with silicone liquids for transformers should be revised and extended to incorporate chapter/abstracts, especially for specific applications. The standards should be complemented with an "acceptable range of values" which is more reflective of current experience in the field.

- Standards concerning viscosity, IEC 69836 and IEC 60944 specifying viscosity limits suitable for silicone liquids show discrepancy and variation in stated value. The general assumption of the standard's suitability to all electrical applications of silicone liquid was found to be weak, especially as heat convection is not critical in a CSE. Viscosity limits of silicone liquid for its use in CSE can be reconsidered. Consequently, modifications in the measurement techniques and upper limit for various properties should be made.

- For dielectric measurements, extra precaution should be taken to avoid the most possible sources of error, the inclusion of a frequency-sensitive error range and repeatability index were found as possible areas of improvement in the current standards.

- The development of standardized test cells for testing breakdown voltage and dielectric parameters could help produce reliable results and facilitate reasonable comparison. This is in conjunction with the realisation that test cells for measuring liquids according to IEC are not adequate for measuring silicone insulation liquids.

- Breakdown voltage alone should not be taken as the sole defining criteria for the validation and comparison of dielectric liquids. Other factors such as measurement temperature, moisture content should weigh in in such 
studies. Arguably, changes in the loss factor are a better indicator for insulation liquid performance than the breakdown voltage.

- The use of standard voltage ramp and unit of defining breakdown strength can enhance understanding and interpretation of values obtained. As mentioned above, for DC conductivity, the test cell constraints and applicability of the setup to detect a measurable current lead to the conclusion that test cells that satisfy current IEC standards are not necessarily suitable for assessing the liquid quality.

- The use of relative moisture content as a unit to assess moisture content could reduce ambiguity in comparison of different properties in contrast with different liquids. This is also relevant in light of increased interest in ester-based insulation liquids e.g., transformers, where absolute moisture content is not a good indicator for dielectric performance.

- Stipulation of acceptable water level content for the dielectric liquid in operation, probably unique to the specific application. Modifications to be made in light of in-field observations considering the acceptable moisture content for liquid insulation used in service-free equipment were realised.

- While sample handling, sources of common error and rectification procedures shall be identified and specified in the standards. The most apparent is the suggested use of sealed glass containers, which is not practicable for large amounts of liquid insulation. Standards should consider the use of polymer containers for sampling and suitable storage, as well as transportation of liquid.

- One key issue that was identified when investigating ageing in CSE, was the incomplete record of the starting conditions for a number of silicone insulation liquids used. This is partly due to the fact that CSE for XLPE cables were considered "maintenance free" accessories, thus it was not considered important at the time. Hindsight shows that CSE are not necessarily maintenance free for the full duration of their specified lifetime, but identifying changes of the insulation liquid over time requires knowledge of the starting point. Thus, proper maintenance of records at the installation is crucial for condition monitoring and post-failure diagnosis, even for equipment that does not have a typical maintenance schedule.

\section{Summary}

Standards relevant to silicone liquids used in CSE from the standpoint of theoretical and empirical research are discussed. This article aimed to identify and suggest reforms based on often unnoticed observations.

\section{References}

[1] CIGRE Technical Brochure 815: Update of service experience of HV underground and submarine cable systems. 2020.

[2] J. Warnock, D. McMillan, J. A. Pilgrim, and S. Shenton, "Review of offshore cable reliability metrics," in IET Conference Publications, 2017.

[3] P. L. Lewin, J. S. Davies, S. M. Rowland, V. M. Catterson, C. Johnstone, and C. Walton, "The State of the Art of Condition Monitoring: Where Do We Go From Here?," in Insucon 2013-International Electrical Insulation Conference, 2013, pp. 58-66.

[4] Shaw A. V. et al., "Techniques to Monitor the Aging of Silicone Oils," in International Conference on Dielectrics, 2020, pp. 704-707.

[5] S. Thakur, G. Callender, T. Andritsch, P. L. Lewin, A. V. Shaw, and O. Cwikowski, "A comparative analysis of different dielectric fluids for cable sealing ends," in Proceedings of the 2020 IEEE 3rd International Conference on Dielectrics, ICD 2020, 2020, pp. 762-765.

[6] J. Shen, J. Luo, M. Tang, F. Lin, and H. Lei, "Analysis of explosion accident of $110 \mathrm{kV}$ power cable termination," High Volt. Appar., vol. 31, no. 11, pp. 74-75, 2005.

[7] K. B. Liland, A. K. Bjørke, S. Hvidsten, H. Faremo, and E. Bjerkan, "Failure Modes and Condition Assessment of High Voltage Oil Filled XLPE Terminations," in IEEE Electrical Insulation Conference, Montreal, 2009, pp. 509-513.

[8] G. W. Nederbragt, "Generation and absorption of gas in insulating oils under the influence of an electric discharge," J. Inst. Electr. Eng., vol. 79, no. 477, pp. 282-290, 1936.

[9] J. G. Rabe, W. F. Schmidt, and T. Suzuki, "Decomposition Products of Silicone Liquids Due to Electric Discharges," IEEE Transactions on Electrical Insulation. pp. 152-157, 1983.

[10] IEEE C57.111-Guide for Acceptance of Silicone Insulating Fluid and Its Maintenance in Transformers. 2009.

[11] Shaw A. V. et al., "Techniques to Monitor the Aging of Silicone Oils," in International Conference on 
Dielectrics, 2020, pp. 704-707.

[12] IEC 69836-Specifications for Silicone liquids for electrical purposes. 1993.

[13] BS EN ISO 3104- Methods for test for petroleum and its products- determination of kinematic viscosity and calculation of dynamic viscosity, vol. 71, no. 1. 1996.

[14] Z. Chen, J. Tang, C. Luo, and J. Zhang, "A Study on Aging Characteristics of Silicone Oil in HV Oil-filled Cable Termination Based on Infrared Thermal Imaging Test," MATEC Web Conf., vol. 22, pp. 1-6, 2015.

[15] S. Thakur, T. Andritsch, P. Lewin, A. Shaw, and O. Cwikowski, "Investigating the Physiochemical Effects of Verdigris Contamination found on a Polymeric Cable Sealing End," in Electrical Insulation Conference, 2021, pp. 206-209.

[16] IEC 60247 Insulating liquids - Measurement of relative permittivity, dielectric dissipation factor (tan $\delta)$ and d.c. resistivity. 2004.

[17] S. Wang, J. Wei, S. Yang, M. Dong, and G. Zhang, "Temperature and thermal aging effects on the frequency domain spectroscopy measurement of oil-paper insulation," in Proceedings of the IEEE International Conference on Properties and Applications of Dielectric Materials, 2009, pp. 329-332.

[18] Z. Chen, J. Tang, C. Luo, and J. Zhang, "A Study on Aging Characteristics of Silicone Oil in HV Oil-filled Cable Termination Based on Infrared Thermal Imaging Test," in MATEC Web of Conferences, 2015.

[19] S. Thakur, P. L. Lewin, T. Andritsch, Shaw A. V., and O. Cikowski, "Investigating the Physiochemical Effects of Aging Silicone Oil Using Sonication as a means of Mimicking Electrical Aging," in Conference on Electrical Insulation and Dielectric Phenomena (CEIDP), 2020.

[20] "Insulating Liquids- Determination of the dielectric dissipation factor by measurement of the conductance and capacitance- Test method," IEC 61620, 1999.

[21] CIGRE, "CIGRE Technical Brochure TB 436, Working Group A2.36- Experiences in Service with New Insulating Liquids," in ISBN: 978-2-85873-124-4, 2010

[22] "Insulating liquids - Determination of the breakdown voltage at power frequency - Test method," $B S E N$ 60156, 2018.

[23] A. Rajab, A. Sulaeman, S. Sudirham, and Suwarno, "A comparison of dielectric properties of palm oil with mineral and synthetic types insulating liquid under temperature variation," ITB J. Eng. Sci., vol. 43, no. 3, pp. 191-208, 2011.

[24] J. P. Crine, H. Saint-Onge, R. Grob, J. Casanovas, P. Lecollier, and J. Mathieu, "Influence of sample preparation and conditioning procedures on the electrical properties of silicone oil," J. Electrostat., vol. 12, pp. 609-619, 1982.

[25] R. M. Hakim, R. G. Olivier, and H. St-Onge, "The Dielectric Properties of Silicone Fluids," IEEE Trans. Electr. Insul., vol. 12, no. 5, pp. 360-370, 1977.

[26] H. Shimokawa, A. Ohashi, and M. Ueda, "Dielectric behaviour in non-pure dielectric liquid films," J. Phys. D. Appl. Phys., vol. 3, no. 1, 1980.

[27] A. Haidar, J. C. Fothergill, L. A. Dissado, and P. Hopewell, "Anomalous dielectric response of very small quantities of virgin, aged and failed silicone oil," IEEE Trans. Dielectr. Electr. Insul., vol. 10, no. 2, pp. 336342, 2003.

[28] ASTM D1169-19a, Standard Test Method for Specific Resistance (Resistivity) of Electrical Insulating Liquids, ASTM Inter. ASTM International, West Conshohocken, PA., 2019.

[29] WG and \17/SC12, "Effect of Particles on Transformer Dielectric Strength," CIGRE Montr. QC Canada, 2000.

[30] Suwarno and M. A. Darmawan, "Effect of water content on dielectric properties and partial discharge characteristics of silicone oil," in 3rd IEEE Conference on Power Engineering and Renewable Energy, ICPERE 2016, 2017.

[31] H. Walker and T. Andritsch, "Evaluation of the Effect of Moisture on Dielectric Properties of Ester Liquids," in Annual Report - Conference on Electrical Insulation and Dielectric Phenomena, CEIDP, 2020, pp. 223-226.

[32] K. B. Liland, K. Eidnes, K. Bjørneklett, and S. Hvidsten, "Measurement of solubility and water content of insulating oils for HV XLPE cable terminations," in Conference Record of IEEE International Symposium on Electrical Insulation, 2008, pp. 7-10.

[33] IEC 60475-Method of sampling insulating liquids. 2011.

[34] J. G. Lang and Freeth;P.D., “Users' experience of $11 \mathrm{kV}$ distribution cable accessories," in IEE Colloquium on 
Cable Accessories up to 33kV, 1993, pp. 1-4.

[35] IEC 60944-Guide for the maintenance of silicone transformer liquids. 1988.

[36] ASTM D923- 15, Standard Practices for Sampling Electrical Insulating Liquids. 2015.

Bios

\begin{tabular}{|c|c|}
\hline $\begin{array}{l}\text { Soumya Thakur } \\
\text { Soum }\end{array}$ & $\begin{array}{l}\text { Graduated in Electrical and Electronics Engineering from Maharaja Surajmal } \\
\text { Institute of Technology and completed her MS and PhD in the High Voltage } \\
\text { Engineering department at the Indian Institute of Technology, Madras, India in } \\
2019 \text {. Her work aimed at improving condition monitoring of transformer insulation } \\
\text { and insulation diagnosis of cable accessories has led to seven journals. She is } \\
\text { currently working as a Research Fellow at the TDHVL of the University of } \\
\text { Southampton, U.K. }\end{array}$ \\
\hline & $\begin{array}{l}\text { Graduated from the University of Southampton in the UK with a first-class MChem } \\
\text { degree in Chemistry in } 2016 \text { and completed her PhD in } 2020 \text { in the Tony Davies } \\
\text { High Voltage Laboratory at the University of Southampton, where she is currently } \\
\text { working. Her PhD research led to four journal paper publications and a keynote talk } \\
\text { at the IEEE ICD in 2018. She is currently contributing to Cigre working group } \\
\text { B1/D1.75 }\end{array}$ \\
\hline Thom & $\begin{array}{l}\text { Received Dipl.-Ing. Degree in Electrical Engineering from the Graz University of } \\
\text { Technology in } 2006 \text { and a PhD degree in the same field from the Delft University } \\
\text { of Technology in } 2010 \text {. He is currently working as an Associate Professor in } \\
\text { Electrical Power Engineering at the University of Southampton. Thomas is currently } \\
\text { the chair of the UK \& Ireland IEEE DEIS Chapter. He is a member of the IEEE } \\
\text { DEIS working group on nanodielectrics, CIGRE WG B1/D1.75 and CIGRE WG } \\
\text { D1.73. }\end{array}$ \\
\hline Georg & $\begin{array}{l}\text { George Callender was born in Basildon, UK in 1991. He received M.Sci (Hons) in } \\
\text { Natural Sciences (Maths and Physics) from the University of Durham, UK in } 2013 . \\
\text { He received a PhD degree in electrical engineering from the University of } \\
\text { Southampton, UK in 2018. He is currently a Lecturer in the Electric Power } \\
\text { Engineering group at the University of Southampton. His research interests include } \\
\text { partial discharge phenomena and the thermal modelling of high voltage plants. }\end{array}$ \\
\hline Paul I & $\begin{array}{l}\text { He received the B.Sc. (Hons) and PhD degrees in EE from the University of } \\
\text { Southampton, UK in } 1986 \text { and } 1994 \text {, respectively. He is the Head of ECS, where he } \\
\text { is also the Director of the Tony Davies HV Laboratory. Since } 1996 \text { he has received } \\
\text { funding and grants totalling }>£ 30 \mathrm{M} \text {, supervised } 50 \text { doctoral graduates and published } \\
\text { over } 500 \text { refereed conference and journal papers. He is a Chartered Engineer, an IET } \\
\text { Fellow, and a former IEEE DEIS President. }\end{array}$ \\
\hline Oliver Cwikowski & $\begin{array}{l}\text { Oliver Cwikowski was born in Ohio, USA, in 1989. He received the M.Eng. (with Hons.) } \\
\text { and PhD degrees in electrical and electronic engineering from the University of Manchester, } \\
\text { Manchester, U.K., in } 2012 \text { and 2016, respectively. He is currently a Senior Innovation } \\
\text { Engineer with National Grid Electricity Transmission, where he leads underground } \\
\text { transmission Innovation. }\end{array}$ \\
\hline
\end{tabular}

